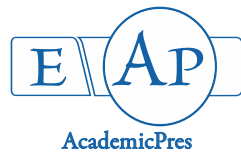

\title{
Veterinarians' Perception, Knowledge and Practices of Hand Hygiene in Enugu State Southeast, Nigeria
}

\author{
Madubuike U. ANYANWU ${ }^{1 *}$, Obichukwu C. NWOBI², \\ Oluwatosin K. AJOKE ${ }^{3}$ \\ ${ }^{1}$ Univeristy of Nigeria, Microbiology Unit, Department of Veterinary Pathology and Microbiology, Nsukka, \\ Nigeria; madubuike.anyanwu@unn.edu.ng ( ${ }^{*}$ correspondingauthor) \\ ${ }^{2}$ Univeristy of Nigeria, Department of Veterinary Public Health and Preventive Medicine, Nsukka, Nigeria; obichukwu.nwobi@unn.edu.ng \\ ${ }^{3}$ University of Nigeria, Veterinary Teaching Hospital, Nsukka, Nigeria; oluwatosin.kolade@unn.edu.ng
}

\begin{abstract}
A cross-sectional survey utilizing questionnaire assessed veterinarians' awareness, attitudes and practices of hand hygiene $(\mathrm{HH})$ in Enugu State Southeastern Nigeria. Data obtained were analyzed using chi-square on SPSS (version 15.0) at a significance level of $P<0.05$ to determine possible associations between variables and perceptions/knowledge about $\mathrm{HH}$. Out of 294 respondents, $26.9 \%$ were familiar with the WHO's " 5 moments of HH" model but majority knew the importance of the model. There was high compliance with $\mathrm{HH}$ after touching an animal (100\%) and animal's surrounding (96\%), and contact with body fluid (100\%) but $\mathrm{HH}$ before touching an animal (52.5\%) and performing clean procedures (58.5\%) were practiced sub-optimally. Majority of the respondents often forgets to perform $\mathrm{HH}(61.9 \%)$ and prioritizes clinical tasks to $\mathrm{HH}$ when busy (65\%). The attitudes/practices towards $\mathrm{HH}$ were generally negative. Minority knew that unclean veterinary personnel's hands are the main route of infection in the veterinary clinic (38.1\%) and alcohol-based hand rubs are more effective on pathogens than other cleansing agents (23.1\%). Majority of the respondents does not know when different $\mathrm{HH}$ techniques ought to be performed. The overall knowledge of $\mathrm{HH}$ by the respondents was moderate (55.4\%). No significant association $(P>0.05)$ was found between level of knowledge and gender, age, qualification, duration of practice and location. Poor knowledge of $\mathrm{HH}$ guidelines, unavailability and inaccessibility of $\mathrm{HH}$ facilities, and unavailability of reminders were the major barriers to compliance with appropriate $\mathrm{HH}$ practices. In conclusion, veterinarians' awareness and perception about $\mathrm{HH}$ in the study area is moderate while the practices are sub-optimal, thus the education of Nigerian veterinarians about $\mathrm{HH}$ and the teaching of the principles and practices of appropriate $\mathrm{HH}$ during veterinary schools are recommended.
\end{abstract}

Keywords: awareness; barrier; hand hygiene; practice; veterinarians

\section{Introduction}

The impact of healthcare-associated infections (HCAIs) includes outrageous increase in healthcare cost due to additional treatment, antimicrobial use, hospital stay and potential death (Mathur, 2011; Stull and Wesse, 2015). In veterinary healthcare, these complications not only affect practice reputation but also drastically affect animal welfare and often create emotional and financial distress for animal owners (Stull and Wesse, 2015). Nowadays, zoonotic multidrug-resistant organisms (MDROs) are the commonest causes of HCAIs in human and veterinary healthcare settings (Anderson, 2015). These organisms often colonize animal patients (especially the skin) and they are readily shed (from the skin and/or through dejections) contaminating the immediate environment (Salman et al., 2018). Animal owners colonized by these organisms are also potential vehicle for their transmission to veterinary clinics (Anderson, 2015). With their hands, veterinarians and veterinary support staffs frequently make contact with their patients (mostly the skin during physical examination and other routine procedures) and contaminated environment (Nakamura et al., 2012; Morley, 2013; Anderson et al., 2014). Quite often, veterinarians also make contact with their clients/animal owners (Morley, 2013; Anderson, 2015). Thus, hands of veterinarians are crucial vehicles for the transmission of organisms to their patients/clients thereby jeopardizing their safety (Anderson, 2015; Salman et al., 2018). These individuals could potentially transmit HCAIs to the public resulting in further spread in human 
and animal population. Veterinarians themselves could contract infectious diseases from their patients/clients if they practice sub-optimal HH (Anderson, 2015; Anderson and Wesse, 2016).

Increasing incidence of multidrug-resistant HCAIs led to the intensified call on human/veterinary health workers to improve on basic hygiene practices (Tartari, 2017; Saito, 2018). Hand hygiene ( $\mathrm{HH})$ has been established the most effective infection prevention and control (IPC) measure that reduces the spread of HCAIs/antimicrobial-resistant organisms in human and veterinary healthcare settings (WHO, 2015; Kingston et al., 2017). HH is a simple, standardized, low-cost and universally applicable measure that breaks the cycle of HCAIs transmission and it is based on solid scientific evidence (Morley, 2013; Anderson, 2015). The World Health Organization (WHO) issued guidelines for effective $\mathrm{HH}$ in order to curb the spread of AMROs/HCAIs and ensure safety of patients, clients and practitioners (WHO, 2009; Cheng et al., 2011; WHO, 2015); the organization has also continued to promote $\mathrm{HH}$ amongst human/veterinary health workers and the public with vast campaigns (WHO, 2015; Tartari et al., 2017; Saito, 2018). Unfortunately, sub-optimal adherence/compliance to recommended $\mathrm{HH}$ procedures by human/veterinary health workers, have been reported in most countries (Boyce and Pittet, 2002; Anderson et al., 2014; Kingston et al., 2017). Studies reported compliance rates of $5-81 \%$ (average $40 \%$ ) and $14-48 \%$ amongst human (Erasmus et al., 2010) and veterinary (Wright et al., 2008; Nakamura et al., 2012; Shea and Shaw, 2012; Anderson et al., 2014) health workers, respectively. This poor compliance has been attributed to complex and multifactorial barriers influenced by elements at both the organizational and individual levels (Mathur, 2011; Chavali et al., 2014). This has resulted in increasing prevalence of HCAIs in human and animal population with the African continent being the worst hit (Allegranzi et al., 2011; Pittet, 2014; Ling et al., 2015). Of all the barriers limiting adherence/compliance to recommended $\mathrm{HH}$ procedures, poor awareness/knowledge of the WHO's "Five Moments of $\mathrm{HH}^{\prime}$ model has been identified as the most important (Maheshwari et al., 2014; Khanal and Thapa, 2017). The model is evidenced-based and entails five calls for action that are universal in ensuring patient, practitioner and client safety (WHO, 2009; Saito et al., 2018). It has been used in understanding, training, monitoring and improving $\mathrm{HH}$ practices among human/veterinary health workers (Anderson et al., 2014; Kingston et al., 2017). Multimodal programs which included ongoing education (about the WHO model and recommended $\mathrm{HH}$ procedures) of health workers have proved to be effective in sustaining improvements on $\mathrm{HH}$ practices in human and veterinary healthcare settings (Anderson et al., 2014; Anderson and Wesse, 2016; Watson, 2016; Khanal and Thapa, 2017).

Knowledge about $\mathrm{HH}$ is crucial for veterinarians because they are anticipated as key animal healthcare providers to take prominent roles in IPC programmes in veterinary healthcare systems and as educators of their clients/the public about $\mathrm{HH}$ (Anderson, 2015; Pires and Pittet, 2017); thus they are supposed to remain informed, trained and motivated (Pires and Pittet, 2017; Saito et al., 2018). In addition, veterinarians have ethical and legal responsibilities to prevent the spread of infectious diseases among animals (Morley, 2013; Bergstrom and Gronlund, 2014). HH practices by health workers are associated with their knowledge and perceptions (Mathur, 2011; Salman et al., 2018). Therefore assessing the veterinarians' perception and level of knowledge/awareness about and practices of $\mathrm{HH}$ is crucial for identifying gaps in knowledge, determining the level of compliance to recommended $\mathrm{HH}$ practices, development of effective $\mathrm{HH}$ policies/practices in veterinary hospitals, and improvement and implementation of appropriate remedies in veterinary schools' curricula (Anderson et al., 2014). This will subsequently result in behavioral change and lead to more appropriate $\mathrm{HH}$ practices (Saito et al., 2018). With proper veterinary health worker (VHW) behaviour and compliance with evidencebased HH guidelines, veterinary HCAIs may be unnecessary adverse events as they are preventable (Ling et al., 2015; Pires and Pittet, 2017).

In available literature, there are several reports (Nair et al., 2014; Diwan et al., 2016; Kingston et al., 2017; Salman et al., 2018) on perception/understanding and practices of $\mathrm{HH}$ among medical/allied health workers in many parts of the world, including in Nigeria (Segun et al., 2013; Shobowale et al., 2015; McFubara et al., 2017); but studies regarding the perception/level of awareness and practices of $\mathrm{HH}$ among veterinary personnel (VP) are scanty and were only conducted in the United States (Wright et al., 2008; Nakamura et al., 2012; Shea and Shaw, 2012) and Canada (Anderson et al., 2014; Anderson and Wesse, 2016). In Nigeria, Veterinary Medicine is a 6-years full-time degree programme during which courses on Public Health and Preventive Medicine are taught. These courses have been taught for several years but there has not been any assessment of Nigerian veterinarians' knowledge about the WHO $\mathrm{HH}$ guidelines. On individual basis, $\mathrm{HH}$ practices taught formally/informally at early stages of life may not be enough for appropriate $\mathrm{HH}$ during veterinary clinical practice. Thus most Nigerian veterinarians may not be knowledgeable about $\mathrm{HH}$ and therefore may be practicing $\mathrm{HH}$ sub-optimally. This sort of practice increases the problem of veterinary HCAIs in the country. Consequently, this could result in increased incidence of HCAIs among animals and humans in the country. Till date, no study has evaluated the Nigerian veterinarians' understanding of the concept and practices of $\mathrm{HH}$. This study was therefore undertaken to assess the perception/level of knowledge, attitude and practices of $\mathrm{HH}$ amongst veterinarians in Enugu State, Southeast Nigeria.

\section{Materials and Methods}

\section{Study area and population}

The study was done in Enugu State, Southeastern Nigeria. Geographically, the state is at coordinates approximately $6^{\circ} 30^{\prime} \mathrm{N} 7^{\circ} 30^{\prime} \mathrm{E}$ and is made up of 17 Local Government Areas (L. G. As) namely: Aninri, Awgu, Enugu East, Enugu North, Enugu South, Ezeagu, Igbo Etiti, 
366

Igbo Eze North, Igbo Eze South, Isi Uzo, Nkanu East, Uzouwani, Nkanu West, Nsukka, Oji River, Udenu and Udi, the Enugu South, Enugu North and Enugu East L. G. As made up Enugu township which is the State Capital Territory. Nsukka L. G. A. comprised Nsukka town with a University Veterinary Teaching Hospital and other smaller towns. Enugu and Nsukka are geographically located at coordinates approximately $6^{\circ} 27^{\prime} 9.60^{\prime \prime} \mathrm{N} 7^{\circ} 30^{\prime} 37.20^{\prime \prime} \mathrm{E}$ and $6^{\circ} 51^{\prime} 24^{\prime} ' \mathrm{~N} 77^{\circ} 23^{\prime} 45^{\prime \prime} \mathrm{E}$, respectively. They are the two most populated towns in Enugu State, with population of about 722,664 and 309,633, respectively (NPC, 2007). The study population comprised veterinarians who graduated from veterinary schools in Nigeria and are teaching and/or practicing in government- and/or privately-owned veterinary clinic in Enugu State. Those veterinarians in privately-owned clinics often handle the animals themselves partly due to lack of veterinary support staffs while those in government clinics (teaching and resident doctors) attend clinical call duty during which they handle their patients with or without the support staffs and/or clinical students on rotation.

\section{Ethical approval}

Ethical approval was not necessary for this study. However, the study was conducted in accordance with the code of ethics of the World Medical Association Declaration of Helsinki (WMA, 2013). Informed consent was obtained from all participants involved in the study and no identifiable data reported.

\section{Study design and sampling procedure}

This is a quantitative descriptive survey aimed to assess the awareness/level of knowledge and practices of $\mathrm{HH}$ amongst veterinarians. Between March and June, 2018, a questionnaire-based cross-sectional study was conducted among teaching and/or practicing veterinarians in Enugu and Nsukka which were purposively selected because majority of veterinarians in the state are based in these towns. A sample size of 384 participants from the two towns was estimated using the method of Thrushfield (1997):

$$
\mathrm{n}=1.96^{2} \times \mathrm{P}_{\exp }\left(1-\mathrm{P}_{\exp }\right) / \mathrm{d}^{2}
$$

Where $\mathrm{n}=$ sample size, $\mathrm{P}_{\exp }=$ expected proportion of knowledge about $\mathrm{HH}$ which was assumed to be $50 \%$ and $\mathrm{d}$ $=$ desired absolute precision level which was assumed to be $5 \%$. Participation implied consent and was voluntary and anonymous.

\section{Data collection}

Information about the level of awareness, practices, and barriers of $\mathrm{HH}$ including the socio-demographic characteristics of the respondents were collected using a selfadministered questionnaire. The questionnaire was developed following a literature review of comparable studies (Nair et al., 2014; ; Maheshwari et al., 2014; Kingston et al., 2017) which assessed the awareness, attitudes and practices of $\mathrm{HH}$, and barriers to adherence to the current WHO (2009) and Centers for Disease Control and Prevention (2002) HH guidelines. The survey comprised 53 questions: 5 questions on demographics, 37 on awareness of $\mathrm{HH}, 24$ on practices of $\mathrm{HH}$, and 17 on hand-rubbing using alcohol-based hand rubs (ABHR) and barriers to compliance with $\mathrm{HH}$ guidelines with Likert scale, multiple choice and 'yes' or 'no' questions. Almost all questions were closed questions with pre-specified answered options (Kingston et al., 2017). However, there was a question where the respondents were meant to define the full meaning of the acronym "ESKAPE" and 2 questions where the respondents could choose the option "others" and respond in their own words. The questionnaire was validated by two experienced researchers and a pilot study on 10 veterinarians. The participants were given opportunity to ask questions after completion of the survey and they were provided with relevant $\mathrm{HH}$ information.

\section{Data analysis}

Data were analysed using SPSS version 15.0. Descriptive statistics (frequencies and percentages) were calculated. An overall knowledge score was evaluated by calculating the total percentages (each counts one point; possible answers ranged from 0-37) of correct answers for the $\mathrm{HH}$ conceptbased questions. Knowledge/awareness score $\geq 75 \%$ was considered good knowledge, 50\%-74\% moderate knowledge, and < 50\% as poor knowledge (Nair et al., 2014; Maheshwari et al., 2014; Salman et al., 2018). Chi-square $\left(\chi^{2}\right)$ was used to determine possible association between variables and the awareness/knowledge about $\mathrm{HH}$. Values of $P<0.05$ were considered significant. Pilot study data was not included in the final analysis.

\section{Results}

\section{Socio-demographic characteristics of respondents}

Out of 400 veterinarians given the survey, 294 (73.5\% response rate) returned sufficiently-filled survey. Of the 294 respondents, majority were males $(215,73 \%)$ and between the ages of 25 and 35 years $(182,62 \%)$ (Table 1). One hundred and fifty-five (52.7\%) were based in Enugu and $139(47 \%)$ were teaching and/or practicing in Nsukka. Majority of the respondents $(191 ; 65 \%)$ had master's degree while $24(8 \%)$ were doctorate degree holders. Fifty-one percent of the respondents have practiced veterinary medicine for more than 5 years.

\section{Perceptions/Level of knowledge possessed by respondents about hand hygiene}

The overall awareness/knowledge level about $\mathrm{HH}$ was $55.3 \%$ (Table 2). Minority (26.9\%) of the respondents agreed that they are familiar with or have heard about the WHO's "5 Moments of HH" model. In order to prevent transmission of pathogens to animals, all the respondents correctly knew that $\mathrm{HH}$ should be done before handling an animal, before a clean/aseptic procedure and after eating/drinking/smoking at work. Majority also correctly knew that performing $\mathrm{HH}$ before handling an animal that had surgery in the last 48 hours (95.9\%) is important for preventing animal infection but not after exposure to immediate surroundings of a sick animal (88.1\%). All the respondents correctly knew that a VHW would not get infected if $\mathrm{HH}$ is performed after handling an animal, before eating/drinking/smoking at work and after contact with urine or faeces of an animal. 
Table 1. Sociodemographic characteristics of the respondents

\begin{tabular}{ccc}
\hline Variable & Frequency & Percentage (\%) \\
\hline Sex & 215 & 73 \\
Male & 79 & 27 \\
\hline Female & Age 294 & 62 \\
\hline & 182 & 31 \\
\hline $35-35$ & 91 & 7 \\
\hline 46 and above & 21 & 27 \\
\hline & Qualification & 65 \\
\hline First Degree & 79 & 8 \\
\hline Masters & 191 & 11 \\
\hline Doctorate & 24 & 38 \\
\hline & Years of practice & 51 \\
\hline Less than 1 & 32 & 47.3 \\
\hline More than 5 & 112 & 52.7
\end{tabular}

Almost all the respondents equally knew that for VP to protect themselves from infections, $\mathrm{HH}$ should be performed after exposure to the surroundings of a sick animal (95.9\%) and after removal of hand gloves (92.2\%).

Regarding survivability of pathogenic organisms in the environment, majority wrongly perceived that Escherichia coli and Klebsiella pneumoniae survives longer in the environment than vancomycin-resistant enterococci (VRE) (0\%) and methicillin-resistant staphylococci (MRS) (35\%). Only a respondent $(0.3 \%)$ was able to correctly define the acronym "ESKAPE". Less than one-third (58.2\%) of the respondents agreed they knew the difference between patient zone and healthcare area. Minority of the respondents knew that unclean hands of a veterinary personnel (VP) is the main route of transmission of pathogens/antimicrobial-resistant organisms between animals, clients and veterinary practitioners $(38.1 \%)$, sick animals are the most frequent source of pathogens in veterinary health-care $(31 \%)$, and an animal can become septic if attending VP's hands are unclean (23.1\%).

With regards to knowledge about $\mathrm{HH}$ techniques, majority (88.1\%) of the respondents claimed that they knew the difference between hand washing $(\mathrm{HW})$ and hand rubbing (HR) but only $54.1 \%$ correctly knew that $\mathrm{HR}$ cleanses the hand more rapidly than HW. Less than half $(41.8 \%)$ of the respondents correctly knew that HR does not cause skin dryness more than $\mathrm{HW}$ while less than onethird (23.1\%) correctly perceived that HR is more effective against pathogens than HW. Eighty-one percent correctly knew that HW and HR were not recommended to be performed in sequence and wearing of gloves does not preclude HW. None of the respondents knew the number of steps involved in appropriate HW procedure and the minimal time needed to perform effective HR. Minority of the respondents knew that HR should be done before examining an animal physically (41.8\%) and before injecting an animal (38.1\%). Minority of the respondents equally knew that $\mathrm{HW}$ is required after removing animal excreta $(35 \%)$ and when managing diarrhoea associated with Clostridium difficile (4.1\%). Half (50\%) of the respondents wrongly perceived that regular use of hand creams increases the likelihood of colonization of hands by microorganisms whereas above two-third knew that artificial fingernails (69\%) and damaged skin (73.1\%) increases hand colonization by pathogens. Less than onethird (23.1\%) of the respondents rightly believed that wearing hand jewellery increase microbial colonization of the hands.

Age, gender, qualification, duration of practice and location did not exert any influence $(P>0.05)$ on the awareness of respondents about $\mathrm{HH}$.

\section{Attitudes and practices of hand hygiene by veterinarians}

Less than half $(41.8 \%)$ of the respondents indicated that they have sufficient knowledge about $\mathrm{HH}$ whereas above half $(54.1 \%)$ reported that they always adhere to appropriate $\mathrm{HH}$ practices (Table 3 ).

Pertaining compliance to the " 5 moments of $\mathrm{HH}$ " model, all the respondents reported that they perform $\mathrm{HH}$ after touching an animal and after contact with body fluids from animals whereas less than two-third indicated that they always perform $\mathrm{HH}$ before handling an animal (52.4\%) and performing clean or aseptic technique (58.5\%). A considerable minority (4\%) of the respondents reported that they do not always perform hand $\mathrm{HH}$ after touching an animal's surrounding.

Less than two-third (58.2\%) of the respondents reported that they do perform $\mathrm{HH}$ often despite the frequency, slightly above half (54.1\%) reported that they do perform $\mathrm{HH}$ in emergency cases despite its cumbersomeness while $31 \%$ reported that they are usually not worried about performing $\mathrm{HH}$ whenever gloves were worn. Almost all $(99.3 \%)$ the respondents indicated that they use reusable cloth towel to dry their hands after washing. More than one-third (65\%) opined that when busy performing clinical tasks should be prioritized to $\mathrm{HH}$, $26.9 \%$ agreed they are always reluctant asking others to perform $\mathrm{HH}, 76.6 \%$ reported that they feel guilty when they omit $\mathrm{HH}(76.9 \%)$ while $73.1 \%$ indicated they feel frustrated when $\mathrm{HH}$ is omitted by others. 
368

A minor proportion (4.1\%) of the respondents believed that staffs in their clinic have been properly trained or instructed in $\mathrm{HH}$ and close to two-third (61.9\%) agreed that they sometimes do miss $\mathrm{HH}$ due to forgetfulness. All the respondents agreed that $\mathrm{HH}$ is essential part of a veterinarian's role and that they are responsible for educating clients and support staffs in their clinic about $\mathrm{HH}$. They equally agreed that appropriate $\mathrm{HH}$ prevents veterinary HCAIs and almost all (98.3\%) agreed that appropriate $\mathrm{HH}$ helps in curbing antimicrobial resistance. Majority agreed that regular enrolment in $\mathrm{HH}$ training is crucial for every veterinarian (88.1\%) but above two-third (69\%) reported that time pressure limits them from enrolling/involving in $\mathrm{HH}$ courses/training. Majority (73.1\%) indicated that they would like to be trained on $\mathrm{HH}$.

Table 2. Perception/Level of knowledge possessed by veterinarians in the study area about hand hygiene

\begin{tabular}{|c|c|c|c|}
\hline \multirow{2}{*}{ Concept } & \multirow{2}{*}{ Correct response } & Frequency & Percentage (\%) \\
\hline & & \multicolumn{2}{|c|}{$\mathrm{n}=294$} \\
\hline Overall knowledge of hand hygiene & Correct answers & 163 & 55.4 \\
\hline $\begin{array}{l}\text { Familiar with or have heard about World Health Organization's "Five } \\
\text { Moments of Hand Hygiene" }\end{array}$ & Yes & 79 & 26.9 \\
\hline Know the full meaning of the acronym "ESKAPE" & $\begin{array}{c}\text { Enterococcus faecium, Staphylococcus aureus, Klebsiella } \\
\text { pneumoniae, Acinetobacter baumanii, Psuedomonas } \\
\text { aeruginosa and Enterobacter }\end{array}$ & 1 & 0.3 \\
\hline Know the difference between patient zone and healthcare area & $\begin{array}{l}\text { Yes (patient zone - a patient's intact skin and its/his/her } \\
\text { immediate surroundings colonized by the patient flora; } \\
\text { healthcare area - containing all other surfaces) }\end{array}$ & 171 & 58.2 \\
\hline $\begin{array}{l}\text { Main route of transmission of antimicrobial-resistant organism between } \\
\text { animal patients, clients and veterinary practitioners }\end{array}$ & Unclean veterinary personnel's hand & 112 & 38.1 \\
\hline $\begin{array}{l}\text { Sick animals are the most frequent source of pathogens in veterinary } \\
\text { health care }\end{array}$ & Yes & 91 & 31 \\
\hline $\begin{array}{l}\text { An animal can become septic if the attending veterinary personnel's } \\
\text { hands are unclean }\end{array}$ & Yes & 68 & 23.1 \\
\hline \multicolumn{4}{|c|}{ Organisms that survive for weeks in human and animal environment } \\
\hline Clostridium difficile & Yes & 103 & 35 \\
\hline Methicillin-resistant staphylococci & Yes & 103 & 35 \\
\hline Vancomycin-resistant enterococci & Yes & 0 & 0 \\
\hline Escherichia coli & No & 56 & 19 \\
\hline Klebsiella pneumoniae & No & 12 & 4.1 \\
\hline \multicolumn{4}{|c|}{ Scenarios in which hand hygiene prevents transmission of pathogens to animals } \\
\hline Before handling any animal & Yes & 294 & 100 \\
\hline Before a clean/aseptic procedure & Yes & 294 & 100 \\
\hline Before handling an animal that had surgery in the last 48 hours & Yes & 282 & 95.9 \\
\hline After eating/drinking/smoking at work & Yes & 294 & 100 \\
\hline After exposure to immediate surroundings of a sick animal & No & 35 & 11.9 \\
\hline \multicolumn{4}{|c|}{ Scenarios in which hand hygiene prevents transmission of pathogens to veterinary personnel } \\
\hline After handling an animal & Yes & 294 & 100 \\
\hline After exposure to the surroundings of a sick animal & Yes & 282 & 95.9 \\
\hline Before eating/drinking/smoking at work & Yes & 294 & 100 \\
\hline After removal of hand gloves & Yes & 271 & 92.2 \\
\hline After contact with urine or faeces of an animal & Yes & 294 & 100 \\
\hline \multicolumn{4}{|c|}{ Hand hygiene techniques } \\
\hline Know the difference between hand washing and rubbing & Yes & 259 & 88.1 \\
\hline Hand rubbing cleanses the hand more rapidly than hand washing & Yes & 159 & 54.1 \\
\hline Hand rubbing causes skin dryness more than hand washing & No & 123 & 41.8 \\
\hline Hand rubbing is more effective against pathogens than hand washing & Yes & 68 & 23.1 \\
\hline $\begin{array}{c}\text { The number of World Health Organization's recommended steps in } \\
\text { appropriate hand washing }\end{array}$ & Seven & 0 & 0 \\
\hline $\begin{array}{l}\text { The World Health Organization recommended that hand washing and } \\
\text { hand rubbing should be performed in sequence }\end{array}$ & No & 238 & 81 \\
\hline $\begin{array}{l}\text { Minimal time needed for alcohol-based hand rub to kill pathogens on a } \\
\text { person's hands }\end{array}$ & 20 seconds & 0 & 0 \\
\hline Wearing gloves replaces hand washing practice & No & 238 & 81 \\
\hline \multicolumn{4}{|c|}{ Appropriate method of hand hygiene in different clinical scenarios } \\
\hline Before physical examination (taking vital signs, palpation) of an animal & Rubbing & 123 & 41.8 \\
\hline Before injecting an animal & Rubbing & 112 & 38.1 \\
\hline After removing animal excreta & Washing & 103 & 35 \\
\hline After removing examination gloves & Rubbing or Washing & 159 & 54.1 \\
\hline After cleaning an in-patient or sick animal's cage or pen & Rubbing & 191 & 65 \\
\hline After visible exposure to animal blood & Washing & 171 & 58.2 \\
\hline Managing Clostridium difficile-associated diarrhoea & Washing & 12 & 4.1 \\
\hline \multicolumn{4}{|c|}{ Factors associated with increased colonization of veterinary healthcare worker's hands by pathogens } \\
\hline Wearing hand jewelry & Yes & 68 & 23.1 \\
\hline Damaged skin & Yes & 215 & 73.1 \\
\hline Artificial fingernails & Yes & 203 & 69 \\
\hline Regular use of a hand cream & No & 147 & 50 \\
\hline
\end{tabular}


Table 3. Practices and attitudes of hand hygiene by veterinarians

\begin{tabular}{|c|c|c|}
\hline \multirow{2}{*}{ Attitudes, Behaviours and Practices } & Frequency & Percentage (\%) \\
\hline & \multicolumn{2}{|c|}{$\mathrm{n}=294$} \\
\hline Adhere to correct hand hygiene practices at all times & 159 & 54.1 \\
\hline Sufficiently knowledgeable about hand hygiene & 123 & 41.8 \\
\hline \multicolumn{3}{|l|}{ Five moments of hand hygiene } \\
\hline i. Perform hand hygiene before handling an animal & 154 & 52.4 \\
\hline $\begin{array}{l}\text { ii. Perform hand hygiene before a clean or aseptic technique (such as injecting an animal, vaccinating an } \\
\text { animal, shaving an animal) }\end{array}$ & 172 & 58.5 \\
\hline iii. Perform hand hygiene after touching an animal & 294 & 100 \\
\hline iv. Always perform hand hygiene after contact with body fluids from animals & 294 & 100 \\
\hline v. Always perform hand hygiene after touching an animal's surrounding & 282 & 96 \\
\hline Perform hand hygiene in emergency cases despite its cumbersomeness & 159 & 54.1 \\
\hline More important to perform my task than to perform hand hygiene when busy & 191 & 65 \\
\hline Not worried about performing hand hygiene whenever gloves are worn & 91 & 31 \\
\hline Dry hands with cloth towels after washing & 292 & 99.3 \\
\hline Feel frustrated when others omit hand hygiene & 215 & 73.1 \\
\hline Reluctant asking others to engage in hand hygiene & 79 & 26.9 \\
\hline Staffs in my/our clinic have been properly trained/instructed in hand hygiene during their training & 12 & 4.1 \\
\hline Feel guilty when hand hygiene is omitted & 226 & 76.9 \\
\hline Miss hand hygiene sometimes due to forgetfulness & 182 & 61.9 \\
\hline Hand hygiene is essential part of a veterinarian's role & 294 & 100 \\
\hline $\begin{array}{l}\text { Education of clients and other staffs in my/our clinic about hand hygiene is part of my role as a } \\
\text { veterinarian }\end{array}$ & 294 & 100 \\
\hline Perform hand hygiene often despite the frequency & 171 & 58.2 \\
\hline Appropriate hand hygiene prevents veterinary healthcare-associated infections & 294 & 100 \\
\hline Regular enrolment in hand hygiene training is crucial for every veterinarian & 259 & 88.1 \\
\hline Appropriate hand hygiene helps in curbing antimicrobial resistance & 289 & 98.3 \\
\hline Time pressure limits me from enrolling/involving in hand hygiene courses & 203 & 69 \\
\hline Would like to be trained on hand hygiene & 215 & 73.1 \\
\hline
\end{tabular}

Barriers of and approaches to improve hand hygiene among veterinarians in the study area

Minority (15\%) of the respondents reported that they have had formal training on $\mathrm{HH}$ and $4.1 \%$ claimed they had training on $\mathrm{HH}$ in the past 3 years. Majority of the respondents reported that there is neither a poster displaying the WHO HH recommendations (85\%) nor an infection notice board $(87 \%)$ in their clinic. Close to half of the respondents (45.9\%) reported that the current location of HW facilities in their clinic is inconvenient. The reasons for poor $\mathrm{HH}$ compliance cited by the respondents were, in rank of decreasing frequency: lack of knowledge of recommended guidelines/protocol (65\%), poor access to hand washing facilities (58.2\%), non-availability of ABHR (45.9\%), non-availability of soap and water (38.1\%), lack of role models among colleagues/superiors (23.1\%), frequent wearing of gloves and gowns by practitioners (19\%), irritation and dryness caused by HW agents (15\%), and understaffing and overcrowding (11.9\%). The respondents cited antiseptic (35\%) as the most commonly used HW agent followed by liquid soap and detergent (26.9\%), soap bar and $\mathrm{ABHR}(8.2 \%)$.

Barriers to the use of ABHR reported by the respondents in rank of decreasing frequency: lack of availability (35.7\%), skin sensitivity (8.2\%) and time (4.1\%). A considerable minority (26.9\%) indicated that there is no barrier to the use of ABHR in their clinic. Personal protection $(41.8 \%)$ ranked first as single most important influencer on the use of $\mathrm{ABHR}$ followed by prevention of cross infection (35\%), convenience (15\%) and infection control policy (11.9\%). Majority of the respondents opined that training and education of veterinarians and veterinary support staffs (69\%), display of instructions demonstrating correct HW techniques in the clinic (58.4\%), provision of accessible ABHR and soap dispensers (54.4\%) were the most effective approaches to improve $\mathrm{HH}$ compliance among veterinarians while minority (35\%) of them suggested that motivation of staffs would have effect on compliance to $\mathrm{HH}$ by veterinarians.

\section{Discussion}

The health and economic burden of multidrug-resistant HCAIs is outrageous thus, veterinarians (as key animal healthcare providers) have been urged to hold the responsibility of $\mathrm{HH}$ (principally targeted to reduce HCAIs and spread of AMR) in veterinary practice area (Anderson et al., 2014; Pires and Pittet, 2017). The results obtained from this study showed that the overall level of awareness or knowledge about $\mathrm{HH}$ amongst veterinarians in the study area is moderate. This could be attributed to the fact that minority of the respondents had heard about the "5 moments of $\mathrm{HH}$ " model. The model aims to increase selfefficacy among practitioners by giving unambiguous advice about when to incorporate $\mathrm{HH}$ into complex care tasks (WHO, 2009; Kingston et al., 2017). The finding of low 
370

familiarity about the model in this study suggested that there is little or no WHO multimodal $\mathrm{HH}$ education/awareness campaign program going on in the study area. It also suggested that the Nigerian veterinary schools' curricula might be deficient with regards to concepts of appropriate $\mathrm{HH}$. Despite the low familiarity with the "5 moments of $\mathrm{HH}$ " model, the respondents exhibited good knowledge about the importance/timing of some components of the model such as performing $\mathrm{HH}$ before handling any animal, before performing a clean/aseptic procedure, after contact with urine or faeces of an animal, after handling an animal and after exposure to the surroundings of a sick animal. This high knowledge about importance of the model's components may be due to personal experiences, motivations, instructional initiatives, influence of other staffs among other reasons. A similar finding was reported by Anderson and Wesse (2016) among veterinary clinic personnel in Canada.

The emergence of "personal protection" as the single most important positive influencer of $\mathrm{HH}$ practice among the respondents in this study implies that these veterinarians strive to protect themselves from risk more traditionally associated with certain aspects of care such as contact with body fluid (Kingston et al., 2017). This may also explain the high compliance to some components of

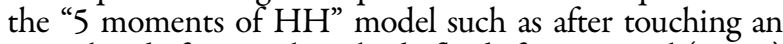
animal and after touching body fluids from animal (100\%) and after touching an animal's surroundings (96\%), and high level of knowledge about the scenarios during which $\mathrm{HH}$ prevents transmission of pathogens. However, some of the respondents might have self-reported a high rate of personal compliance, but it has been noted that $\mathrm{HH}$ beliefs, knowledge and practices do not always correlate (Jeong and Kim, 2016; Kingston et al., 2017). Despite 35\% of the respondents identifying "prevention of cross infection" as the single most important positive influencer of $\mathrm{HH}$ practice and almost all exhibiting high knowledge of the importance/timing of $\mathrm{HH}, 47.6 \%$ were non-compliant with $\mathrm{HH}$ "before handling an animal", 41.5\% "before performing a clean or aseptic procedure (such as vaccinating an animal, injecting an animal)" and $4 \%$ "after touching the surrounding of an animal". This suggested that some of these veterinarians may perceive less risk associated with these indications and may not realize the potential of veterinary HCAI transmission associated with these animal encounters (Kingston et al., 2017). While there are no existing recommendations to perform $\mathrm{HH}$ before administration of vaccine to animals, $\mathrm{HH}$ is recommended before administration of injections (Anderson $e$ t al., 2014). By video observation, Anderson et al. (2014) reported 3\% and $26 \%$ compliance to $\mathrm{HH}$ before and after animal contact which is lesser than $52.4 \%$ and $96 \%$ recorded in the hereby study, respectively. Anderson et al. (2014) also reported that unnecessary or mistimed contact with animals (such as petting of animals at the end of appointment and immediately after performing $\mathrm{HH}$ ) resulted in missed opportunity with compliance among veterinarians. It has been suggested that these unnecessary contacts with animals should be avoided especially if individuals are not ready to comply with appropriate $\mathrm{HH}$ (Anderson et al., 2014). The finding of non-compliance by some veterinarians in this study calls for concern because it has been proven that the veterinary hospital environment can contribute significantly to disease transmission (Anderson, 2015). The potential high infection-risk areas in the veterinary clinic environment are the patient zone (animal's intact skin and its immediate surroundings colonized by the flora) and healthcare area (containing all other surfaces) (Kirk et al., 2016). Unfortunately, less than one-third of the respondents in this study actually knew the difference between a patient zone and healthcare area.

It is worrisome that a minor proportion $(11.8 \%)$ of respondents in this study cited "infection control policy" as the single most important influencer to use $\mathrm{ABHR}$ (sanitizers). ABHR rapidly inactivate a variety of potentially harmful microorganisms and in all $\mathrm{WHO} \mathrm{HH}$ policies, the use of ABHR is recommended as the "gold standard" for $\mathrm{HH}$ in human/veterinary healthcare settings (WHO, 2009; Kingston et al., 2017). It is a matter of concern that respondents in this study did not identify "safety of the patients" nor "evidence-based practice" as positive influencers for the use of ABHR. This suggested that veterinarians in the study area perhaps do not know/consider that their patients' safety should be paramount during clinical practice. The major reason why the WHO developed evidence-based models (" 5 moments of $\mathrm{HH}^{\prime \prime}$ and procedural $\mathrm{HH}$ practices) is to prevent transmission of HCAI to patients thereby ensuring their safety (Kingston et al., 2017). These findings further prove that these veterinarians do not have adequate knowledge about $\mathrm{HH}$ and are practicing $\mathrm{HH}$ sub-optimally thereby worsening the problem of cross-transmission of pathogens between animals and humans.

It is disconcerting that most respondents in this study do not know the appropriate $\mathrm{HH}$ technique to employ in different clinical tasks/scenarios such as prior to physical examination of an animal, injecting an animal, and managing Clostridum-difficile-associated diarrhoea (Nair et al., 2013; Maheshwari et al., 2014; Anderson et al., 2014; Kingston et al., 2017). It is equally disturbing that only twothird of respondents in this study knew that HR and HW are the appropriate techniques of $\mathrm{HH}$ after cleaning a sick animal's surrounding and after visible exposure to animal blood, respectively (WHO, 2009; Nair et al., 2013; Maheshwari et al., 2014). This finding puts a doubt to the response of $54.1 \%$ and $41.8 \%$ of respondents who claimed that they adhere to correct $\mathrm{HH}$ practices at all times and have sufficient knowledge about $\mathrm{HH}$, respectively. Although $\mathrm{HH}$ using $\mathrm{ABHR}$ is recommended for routine $\mathrm{HH}$ in healthcare settings, HW with soap and water is recommended when the hands are visibly soiled or when an alcohol-resistant pathogen (such as non-enveloped viruses e.g. canine parvovirus, and Clostridium species) may be present (Anderson et al., 2014). ABHR is contraindicated when managing patients with Clostridium difficileassociated diarrhoea (Kingston et al., 2017). Displaying of posters specifying contraindications for the use of $A B H R$ in veterinary clinics should be an important component of future educational campaign or intervention in the study area (Anderson et al., 2014).

The acronym "ESKAPE" (Enterococcus faecium, Staphylococcus aureus, Klebsiella pneumoniae, Acinetobacter baumanii, Psuedomonas aeruginosa and Enterobacter) are 
"high priority" pathogens that pose threat to human and animal health against which the WHO has continued to urge human/veterinary health workers to step up their IPC practices (particularly $\mathrm{HH}$ ) thereby controlling the spread of these organisms (WHO, 2017). Unfortunately, only a respondent in this study correctly knew the full meaning of the acronym and none of the respondents knew that VRE ranks first among organisms that survive for long time in the environment followed by MRS (Mathur, 2011). This finding suggested that veterinarians in the study area are deficient in knowledge about problematic pathogens that are easily spread in the hospital environment. This finding calls for intensified training of these veterinarians on $\mathrm{HH}$ from a "One-Health" perspective because these organisms are the commonest causes of HCAIs. It raises serious concern that less than one-third of the respondents in this study knew that unclean hands of VP are the main source of pathogens in veterinary clinic and an animal could become septic if attending VP's hands are unclean. The WHO has through awareness campaigns urged health-care providers to perform $\mathrm{HH}$ in order to prevent patients (especially those that had surgery) from developing sepsis (Saito et al., 2018). Encouragingly, almost all the respondents knew that $\mathrm{HH}$ should be performed before handling an animal that had surgery in the last 48 hours.

It calls for serious concern that close to one third (31\%) of respondents in this study reported that they do not worry about performing $\mathrm{HH}$ whenever gloves were worn and 19\% identified frequent wearing of gloves and gowns by practitioners as reason for non-compliance to appropriate $\mathrm{HH}$. After glove removal, 39\% compliance to $\mathrm{HH}$ was observed among veterinarians (Anderson et al., 2014) while 82.3\% VP self-reported that $\mathrm{HH}$ is important after glove removal (Anderson and Wesse, 2016). It has been noted that glove use may be misconstrued as a substitute for $\mathrm{HH}$ (Anderson et al., 2014). Although gloves are useful in preventing hand contamination from patients and/or objects, studies have shown that $\mathrm{HH}$ following glove removal is very important because gloves are imperfect barrier owing to the fact that they could have preexisting defect or unnoticed damage during use as well as potential for contamination of the hands during removal since they are often worn for "dirty" procedures (Anderson et al., 2014; Hinkin et al., 2014). For gowns, long sleeves have been reported to interfere with $\mathrm{HH}$ (scrubbing) at the wrist level and therefore should be avoided (Anderson et al., 2014; Bouwera et al., 2017).

Even more worrisome is that none of the respondents in this study knew that the WHO recommended seven unambiguous steps to perform effective HW (Cheng et al., 2011; Nair et al., 2013; Maheshwari et al., 2014). This suggested that these veterinarians may not be performing $\mathrm{HW}$ appropriately. It is crucial to use appropriate technique during $\mathrm{HH}$ in order to ensure that all parts of the hands come in contact with the product used and are adequately decontaminated (Anderson et al., 2014). Studies showed that base of the thumbs, back of the hands, between the fingers and beneath the fingernails are the areas likely to be missed if the recommended steps are not followed during $\mathrm{HH}$ (Anderson et al., 2014). In future $\mathrm{HH}$ training programmes for Nigerian veterinary personnel, emphasis should be made on these parts of the hands most often missed during $\mathrm{HH}$.

Studies have shown that bacteria are transferred from hands to surfaces much more readily when hands remain wet, thus hand drying (HD) has been established an important component of $\mathrm{HH}$ (Kampf et al., 2004). Reusable cloth towel potentially act as a formite between individual users and thus not recommended for HD in healthcare setting (Patrick et al., 1997; Anderson et al., 2014). Unfortunately, $99.3 \%$ of the respondents in this study reported that they use reusable cloth towel for HD. This further proves that veterinarians in the study area are performing $\mathrm{HH}$ sub-optimally. The recommended material for use in HD after HW in human/veterinary healthcare setting is single-use disposable hand towel (Anderson et al., 2014). It is also recommended that after $\mathrm{HD}$, the disposable towel should be used to open faucets of taps and door knobs so as to avoid recontamination of the dried hand (Bouwera et al., 2017). Elsewhere, $1 \%$ of veterinary clinic personnel performed HD after HW using disposable towel while 23\% used reusable cloth towel (Anderson et al., 2014) indicating that these VP adhere to recommended HW guidelines better than respondents in this study. During educational campaigns and training of VP in Nigeria, information on appropriate $\mathrm{HD}$ techniques and ways of preventing recontamination of hands from water faucets should be emphasized (Anderson et al., 2014).

Although in the minority, it calls for concern that $21 \%$ of the respondents in this study wrongly perceived that HW and $\mathrm{HR}$ are recommended to be performed in sequence. $\mathrm{HR}$ is performed as a standalone technique and is not combined with any other approach to $\mathrm{HH}$ (Kingston et al., 2017). The use of ABHR after HW is not necessary and is not recommended (Anderson et al., 2014). In fact, it has been reported that this practice can potentially curb contact time (reducing the effect of cleansing agent on microorganisms) and may result in additional damage to the skin which can lead to increased carriage of pathogens on the hands and reluctance to perform $\mathrm{HH}$ subsequently due to discomfort (Anderson et al., 2014).

With regards to the advantages of the different $\mathrm{HH}$ techniques, only $54.1 \%$ of respondents in this study correctly knew that HR cleanses the hands more rapidly than HW while majority incorrectly believed that HR causes skin dryness more than HW which is more effective against pathogens. Kampf et al. (2004) reported that simply rinsing hands alone with water can remove some superficial skin cells and loosely-adherent bacteria through mechanical action. In clinical setting, the use of soap (either antimicrobial or non-antimicrobial depending on the specific situation) is recommended but reports also showed that if hands are not adequately dried after rinsing alone, the risk of pathogen transmission may even be increased (Patrick et al., 1997; Anderson et al., 2014). Contrarily, rubbing of hands with ABHR (which is antimicrobial in nature) results in rapid deactivation of various types of microorganisms and evaporates soon afterwards with no need of drying (Anderson et al., 2014). Thus ABHR are recommended for day to day hand decontamination (Kingston et al., 2017). 
372

Of all the factors that can increase the likelihood of colonization of a VHW's hands asked in this study, "wearing of hand jewelry" was the least identified (23.1\%). The issue of whether a HCW should wear ring or not remains unresolved because, no study has yet shown an effect of rings on pathogen transmission via hands in the clinical setting (Boyce and Pittet, 2002; Anderson et al., 2014). However, hand jewelleries have been shown to increase bacterial load on the hands (Anderson et al., 2014). Those jewelleries worn at the wrist (such as bracelets and watches) could potentially interfere with HW (scrubbing) and sanitizing at the wrist level (Boyce and Pittet, 2002). Nevertheless, some infection control guidelines recommended removal of hand jewelleries (particularly those that are elaborately designed or made from materials that absorb liquid and cannot be adequately cleaned if contaminated) prior to contact with patient or $\mathrm{HH}$ (Anderson $e t$ al., 2014). As identified by majority in this study, artificial fingernails are not to be worn by practitioners because they are reservoirs for microorganisms (Mathur, 2011). Half of the respondents in this study do not know that the use of hand cream does not increase the likelihood of hand colonization by microorganisms (Nair et al., 2013; Maheshwari et al., 2014). This further indicated the need for urgent training of Nigerian veterinarians about $\mathrm{HH}$ in order to reduce the spread of MDROs and HCAIs.

The most frequently identified barrier to the use of ABHR in this study was lack of availability. As reported by most respondents in this study, antiseptics, liquid soap and detergents are frequently used products for $\mathrm{HH}$ in most veterinary clinics in the study area. It has been noted that there is high likelihood that clinics without ABHR will have poor infection control culture (Anderson et al., 2014). Unfortunately too, close to half of the respondents in this study reported that the location of HW facilities in their clinic is inconvenient and an inconveniently-placed (hidden) HW facility has been associated with reduced compliance (Pires and Pittet, 2017). For best practices, HH products (ABHR, running water, soaps) must be available at the point-of-care (POC) (where the animal, VP, and the provision of care or treatment come together) within armsreach without leaving the animal's zone (Kirk et al., 2016). This will not only promote and facilitate $\mathrm{HH}$ but also prevent the potential spread of microbes that may occur if an individual is forced to move to another area to find a $\mathrm{HH}$ station (Mathur, 2011; Anderson et al., 2014). Encouragingly, majority of the respondents in this study recognized that provision of accessible $\mathrm{HH}$ products would enhance compliance to $\mathrm{HH}$ practices.

Skin sensitivity ranked second among barriers to the use of $\mathrm{ABHR}$ in this study. Evidences showed that ABHR causes less dermatological issue than soap/detergents/antiseptics but $32.5 \%$ of Irish nursing students also cited skin sensitivity as a barrier to the use of ABHR (Kingston et al., 2017). Circulation of counterfeit products, including $\mathrm{ABHR}$, is a major public health problem in Nigeria. These counterfeit ABHR can potentially cause skin sensitivity and damage. Thus, it has been suggested that there may be scope to review the current ABHR products while continuously ensuring that the WHO guidelines are followed and product selection optimized (Kingston et al., 2017).
$\mathrm{ABHR}$ has been shown to significantly reduce the time taken for $\mathrm{HH}$ (Kingston et al., 2017). It is therefore worrisome that $4.1 \%$ of respondents in this study identified "time" as a barrier to the use of ABHR and almost two-third (65\%) had the opinion that clinical task supersede $\mathrm{HH}$ when busy. This wrong perceptions and attitude may be why less than two-third of the respondents frequently performs $\mathrm{HH}$ during or in absence of emergency cases. It has been noted that individuals who believes that $\mathrm{HH}$ takes longer than is truly required may be less likely to attempt $\mathrm{HH}$ at all when busy (Anderson and Wesse, 2016). Nakamura et al. (2012) reported that $72 \%$ of veterinary support staffs cited being too busy as the most prominent reason for not performing $\mathrm{HH}$. The WHO Guidelines on $\mathrm{HH}$ recommended 40-60 seconds for complete HW (from wetting hands to completion of drying) and 20-30s for completion of HR using sanitizers (WHO, 2009; Anderson et al., 2014). Thus, the time burden to perform appropriate $\mathrm{HH}$ is not too onerous therefore Nigerian veterinarians should endeavour to comply with the recommendations (Kingston et al., 2017). ABHR is the primary recommendation for routine $\mathrm{HH}$ as it takes less time, causes less skin damage and can easily be used at the point of care even when a sink is not available, saves water and generates less waste because disposable towels are not required for $\mathrm{HD}$ (Anderson et al., 2014). Therefore, it is worrying that majority of the respondents in this study wrongly thought that HW is more effective than HR. Elsewhere, a $21 \%$ increase in compliance to $\mathrm{HH}$ was reported following a multimodal educational campaign in a veterinary teaching hospital in which the use of foaming ABHR was emphasized (Anderson et al., 2014).

In this study, $26.9 \%$ of the respondents cited "no barrier" to the use of ABHR. This suggested that negligence on the part of some veterinarians in the study area affects compliance to recommended $\mathrm{HH}$ procedures (Kingston $e t$ al., 2017). It may also suggest that these individuals have excellent $\mathrm{HH}$ compliance which has been reported to be highly unlikely among VP (Anderson et al., 2014). Therefore, this perceived lack of barriers may partly be due to lack of awareness of when different $\mathrm{HH}$ techniques ought to be performed (Anderson and Wesse, 2016; Kingston et al., 2017). This is the most probable reason because almost all the respondents in this study had never had formal training on $\mathrm{HH}$ nor had any $\mathrm{HH}$ training in the past 3 years. It may also be due to deficient curricula of the Nigerian veterinary schools on $\mathrm{HH}$ concepts and/or poor awareness campaign on $\mathrm{HH}$ in the study area. In addition, as indicated by majority of respondents in this study, there are no WHO recommended $\mathrm{HH}$ procedure or infection control posters/notice boards displayed in most veterinary clinics in the study area. $\mathrm{HH}$ posters/notice boards are considered a reasonable "first step" in human/veterinary healthcare facilities especially in facilities that may be resistant to more involved active interventions due to lack of a strong infection control culture or other reasons (Anderson et al., 2014). This is because posters/notice boards are a commonly used type of intervention for promoting a wide variety of ideas and behaviours in many settings and they are often incorporated into multimodal interventions for improving $\mathrm{HH}$ compliance in healthcare 
facilities (Mathur, 2011; Anderson et al., 2014). Interestingly, more than half of the respondents in this study recognized that displaying instructions on correct $\mathrm{HH}$ techniques in the clinic can facilitate and promote compliance to $\mathrm{HH}$ practices. The lack of reminders in the veterinary clinics in the study area could also explain why close to two-third of the respondents sometimes miss $\mathrm{HH}$ due to forgetfulness. Anderson and Wesse (2016) suggested that to combat the problem of forgetfulness by veterinarians to perform $\mathrm{HH}$, there is need to make $\mathrm{HH}$ a pervasive component of the clinic culture thereby going beyond reminders (written, verbal or other forms), in this way $\mathrm{HH}$ becomes habitual and does not need to be consciously reminded. Moreover, veterinarians should always remember to perform $\mathrm{HH}$ as they are frequently seen as clinic leaders, knowing that their attitude and behaviours are likely to be more influential than others (Anderson, 2015; Anderson and Wesse, 2016).

Lack of association between the variables (age, gender, qualification, year of practice and location) and awareness/knowledge of respondents in this study about $\mathrm{HH}$ may be because the respondents were similarly not exposed to the WHO HH model in the veterinary schools. This suggested that knowledge was a function of focused training on $\mathrm{HH}$ and not gender, age, qualification, year of practice or location. This study did not assess the association between the variables and compliance (practice) to recommended $\mathrm{HH}$ guidelines because of high likelihood of inflation of self-compliance (Anderson and Wesse, 2016).

Veterinarians are key animal healthcare providers thus they are expected to be trained in order to lead in IPC programs in veterinary healthcare systems (Morley, 2013; Saito et al., 2018). Interestingly, more than half of the respondents in this study believed that staffs in their clinic are not well trained on $\mathrm{HH}$ and majority indicated that they would like to be trained on $\mathrm{HH}$. By taking advantage of these optimistic views and other positive attitudes (such as appropriate $\mathrm{HH}$ helps in curbing $\mathrm{AMR}, \mathrm{HH}$ is essential part of a veterinarian's role, feel guilty when $\mathrm{HH}$ is omitted, and education of their staffs and clients is part of a veterinarian's role) by majority in this study, the Federal Ministry of Health in collaboration with the Veterinary Council of Nigeria, Veterinary hospital administrations and other stakeholders should provide strategies on how they should intensify education of veterinary/allied animal health workers on the WHO $\mathrm{HH}$ Guidelines. These veterinarians would likely be receptive to the training since majority opined that training and education of VP will facilitate compliance to $\mathrm{HH}$ guidelines in their clinics.

This study highlighted an area where availability of literature is limited. The survey was anonymous and voluntary thus the likelihood of the respondents giving socially desirable answers was reduced. The study population is practicing/teaching veterinarians thus providing a better estimate of their knowledge about $\mathrm{HH}$ after graduation from veterinary schools. The data were collected from participants approached randomly therefore they may not account for the differences in the population. There is possibility of bias since the study is self-reported and some participants could inflate self-compliance (Anderson et al., 2014). It is also possible that veterinarians with greater interest in infection control or who were more comfortable with their current practices would be more willing to participate (Anderson and Wesse, 2016). Thus, generalization of the result to all veterinarians in Nigeria should be done with caution since only Enugu State was sampled. Despite the identified limitations of the findings, this study could be useful in improving compliance to $\mathrm{HH}$ guidelines in veterinary settings in Nigeria.

\section{Conclusions}

The overall perception/awareness of veterinarians in Enugu State, Southeastern Nigeria about $\mathrm{HH}$ is moderate. This is attributed to lack of education/training on $\mathrm{HH}$ and absence of established IPC programmes and campaign on awareness of $\mathrm{HH}$ in the country. Consequently, veterinarians in the study area are practicing $\mathrm{HH}$ suboptimally, thereby increasing the problem of veterinary HCAIs. Thus, there is urgent need for intensified education/training of veterinarians in Nigeria on $\mathrm{HH}$ and the teaching of the concepts and practices of appropriate $\mathrm{HH}$ should begin during the Veterinary schools.

\section{Conflict of Interest}

The authors declare that there are no conflicts of interest related to this article.

\section{References}

Allegranzi B, Bagheri NS, Combescure C, Graafmans W, Attar H, Donaldson L, Pittet D (2011). Burden of endemic health-careassociated infection in developing countries: systematic review and metaanalysis. Lancet 377(9761):228-241.

Anderson MEC (2015). Contact precautions and hand hygiene in veterinary clinics. Veterinary Clinics of North America: Small Animal Practice 45(2):343-360.

Anderson MEC, Sargeant JM, Wesse JS (2014). Video observation of hand hygiene practices during routine companion animal appointments and the effect of a poster intervention on hand hygiene compliance. BMC Veterinary Research 10(1):106.

Anderson MEC, Weese JS (2016). Self-reported hand hygiene perceptions and barriers among companion animal veterinary clinic personnel in Ontario, Canada. Canadian Veterinary Journal 57(3):282-288.

Bahal A, Karamchandani D, Fraie AP, McLaws M-L (2007). Hand hygiene compliance: universally better post- contact than pre-contact in healthcare workers in UK and Australia. British Journal of Infection Control 8(1):2428.

Bergström K, Grönlund U (2014). A pre- and post-intervention study of infection control in equine hospitals in Sweden. Acta Veterinaria Scandinavica 56(1):52.

Bouwera M, Labuschagnea S, Spamera S, Vermaaka C, Zietsmana L-M, Steynb D, Joubert G (2017). Knowledge of final-year medical students at the University of the Free State of hand hygiene as a basic infection control measure. South African Family Practice 1(1):1-5.

Boyce JM, Pittet D (2002). Healthcare infection control practices advisory committee, HICPAC SHEA APIC IDSA hand hygiene task force. guideline for hand hygiene in health-care settings. Recommendations of 
374

the healthcare infection control practices advisory committee and the HICPAC/SHEA/APIC/IDSA hand hygiene task force. American Journal of Infection Control 30:S1-S46.

Centre for Disease Control (2002). Guideline for hand hygiene in healthcare settings: recommendations of the healthcare infection control practices advisory committee and the HICPA/SHEA/APIC/IDSA hand hygiene task force. http: //www. cdc.gov/ handhygiene/ providers/guideline.html.

Chavali S, Menon V, Shukla U (2014). Hand hygiene compliance among healthcare workers in an accredited tertiary care hospital. Indian Journal ofCritical Care Medicine 18(10):689-693.

ChengVC, TaiJW,HoSK, Chan JF, Hung KN, Ho PL, Yuen KY (2011). Introduction of an electronic monitoring system for monitoring compliance with moments 1 and 4 of the WHO "My 5 Moments for Hand Hygiene" methodology. BMC Infectious Diseases 11(1):151.

Diwan V, Gustafsson C, Rosales Klintz S, Joshi SC, Joshi R, Sharma M,... Lundborg CS (2016). Understanding healthcare workers self-reported practices, knowledge and attitude about hand hygiene in a medical settingin rural India. PLoSONE 11(10):e0163347.

Erasmus V, Daha TJ, Brug H, Richardus JH, Berendht MD, Vos MC, van BeeckES (2010). Systematic review of studies on compliance with hand hygiene. Infection Control and hospital Epidemiology 31(3):283-294.

FitzGerald G, Moore G, Wilson AP (2013). Hand hygiene after touching patients surroundings: the opportunities most commonly missed. Journal of Hospital Infection 84(1):27-31.

Hinkin J, Curtter J (2014). How do university education and clinical experience influence pre-registration nursing students infection control practice? A descriptive cross sectional survey. Nurse Education Today 34(2):196-201.

Jeong SY, Kim KM (2016). Influencing factors of hand hygiene behavior of nursing students based on theory of planned behavior: A descriptive surveystudy. Nurse Education Today 36:159-64.

Kampf G, Kramer A (2004). Epidemiologic background of hand hygiene and evaluation of the most important agents for scrubs and rubs. Clinical Microbiology Reviews 17(4):863-893.

Khanal G, Thapa $S$ (2017). Awareness of hand hygiene among health care workers ofChitwan, Nepal.SAGE Open 7(4):2158244017735141

Kingston LM, O'Connell NH, Dunne CP (2017). Survey of attitudes and practices of Irish nursingstudents towards hand hygiene, including hand rubbing with alcohol-based hand rub. Nurse Education Today 52:5762.

Kirk J, Kendall A, Marx JF, Pincock T, Young E, Hughes JM, Landers T (2016). Point of care hand hygiene-where's the rub? A survey of US and Canadian health care workers' knowledge, attitudes, and practices. American Journal of Infection Control 44:1095-101.

Ling ML,ApisarnthanarakA, Madriaga G (2015). The burden of healthcare-associated infections in Southeast Asia: A systematic literature review and meta-analysis. Clinical and Infectious Diseases 60(11):16901699.

Maheshwari V, Kaore NC, Ramnani VK, Gupta SK, Borle A, Kaushal R (2014). A study to assess knowledge and attitude regarding hand hygiene amongst residents and nursing staff in a tertiary health care setting of Bhopal City. Journal of Clinical and Diagnostic Research 8(8):DC04DC07.
Mathur P (2011). Hand hygiene: back to the basics of infection control. Indian Journal of Medical Research 134(5):611-620.

McFubara KG, Ogbe DK, Mbooh RT, Nwizia BP, Nasamu UP, Ogori DS (2017). Hand washing among health workers in tertiary health facilities in Bayelsa State, Nigeria. International Journal of Community Medicine andPublic Health 4(5):1459-1465.

Morley PS (2013). Evidence-based infection control in clinical practice: If you buy clothes for the emperor, will he wear them? Journal of Veterinary Internal Medicine 27(3):430-438.

Nair SS, Hanumantappa R, Hiremath SG, Siraj MA, Raghunath P (2014). Knowledge, attitude, and practice of hand hygiene among medical and nursing students at a tertiary health care centre in Raichur, India. ISRN Preventive Medicine http:// dx.doi. org/ $10.1155 / 2014 / 608927$.

Nakamura RK, Tompkins E, Braasch EL, MartinezJr.JG, Bianco D (2012). Hand hygiene practices of veterinary support staff in small animal private practice.Journal of Small Animal Practice 53(2):155-160.

Nigerian Population Commission (2007). Federal Republic of Nigeria (NPC/FRN) (2007). Special FRN, Gazette no. 23 on the 2006 population census.

PatrickDR, Findon G, Miller TE (1997). Residual moisture determines the level of touch-contact-associated bacterial transfer following hand washing. Epidemiology and Infection 119(3):319-325.

Pires D, Pittet D (2017). Hand hygiene mantra: teach, monitor, improve, and celebrate. Journal of Hospital Infection 95(4):335-337.

Pittet D (2014). Burden of endemic healthcare-associated infection in Africa. 16th ICID Abstracts/International Journal of Infectious Disease 21:51.

Saito H, Kilpatrick C, Pittet D (2018). The 2018 World Health Organization SAVE LIVES: clean your hands campaign targets sepsis in health care. Intensive Care Medicine 44:499-501.

Salman M, Raza MH, Mustafa ZU, Shrestha S, Ali M, Fahham H, ....Hussain K (2018). Knowledge, attitudes and practices of hand hygiene among Pakistani health professionals: A cross-sectional study. Journal of Infection in Developing Countries 12(1):063-066.

Segun B, Effa EE, Okokon EO, Oduwole OA (2013). Handwashing practice among healthcare providers in a teaching hospital in southern Nigeria. International Journal of Infection Control v9:i4 doi: 10.3396/IJIC.v9i4.031.139:i4

Shea A, Shaw $S$ (2012). Evaluation of an educational campaign to increase hand hygiene at a small animal veterinary teaching hospital. Journal of American Veterinary Medical Association 240(1):61-64.

Shobowale EO, Adegunle B, Onyedibe K (2016). An assessment of hand hygiene practices of healthcare workers of a semi-urban teaching hospital using the five moments of hand hygiene. Nigerian Medical Journal 57(3):150-154

Stull JW, Weese JS (2015). Hospital-associated infections in small animal practice. Veterinary Clinics of North America: Small Animal Practice 45(2):217-233

Tartari E, Pires D, Pittet D (2017). Clean your hands 5th May 2017: 'Fight antibiotic resistance - it's in your hands'. Antimicrobial Resistance and Infection Control 6:39.

Watson JA(2016). Role of a multimodal educational strategy on health care workers' handwashing American Journal of Infection Control 44(4):400-404. 
World Health Organization (WHO) (2009). Patient safety. Hand hygiene: why, how and when. Geneva, WHO, 2009. http://who.int/gpsc/5may/Hand_Hygiene_Why_How_and_Whe n_Brochure.pdf

World Health Organization (WHO) (2017). Global priority list of antibiotic-resistant bacteria to guide research, discovery, and development of new antibiotics. WHO 2017, http://www.who.int/medicines/ publications/WHO-PPLShort_Summary_25FebET_NM_WHO.pdf.

World Health Organization (WHO) (2017). Save lives: Clean your hands WHO's global annual campaign advocacy toolkit. http://www.who.int/gpsc/5may_advocacy-toolkit.pdf.
World Medical Association (WMA) (2013). World Medical Association Declaration of Helsinki: Ethical principles for medical research involving human subjects. Journal of American Medical Association 310(20):2191-2194.

Wright JG, Jung S, Holman RC, Marano NN, McQuiston JH (2008). Infection control practices and zoonotic disease risks among veterinarians in the United States.Journal of American Veterinary Medical Association 232(12):1863-1872. 